\title{
The intonation of yes and no in an archaic Russian dialect
}

\author{
Knyazev S. V. \\ Vinogradov Russian Language Institute, \\ Russian Academy of Sciences, \\ Moscow, Russia \\ svknia@gmail. com
}

\author{
Pronina M. K. \\ Universitat Pompeu Fabra, \\ Barcelona, Spain \\ mariia.pronina@upf.edu
}

\begin{abstract}
The present paper analyzes the intonation of pragmatic particles $d a$ "yes" and net "no" found in the spontaneous dialogue speech corpus of a Northern Russian dialect, in which each word bears a pitch accent. Intonation that marks such particles sounds unusual for speakers of Standard Russian and is perceived by them as blunt and impolite. The main aim was to find a consistent pattern explaining the distribution of falling and rising pitch accents on such particles in a dialect of Vaduga (Arkhangelsk region). We tested three hypotheses that can account for this distribution: (a) semantic explanation (the type of pitch accent depends on the semantics of the very particle); (b) communicative explanation (it depends on the communicative function of the preceding utterance, that is, whether it is a question or not); (c) phonetic explanation (it depends on the pitch accent of the preceding utterance). A total of 240 utterances from 3 speakers were analyzed. Results showed that the semantics of the particle is not a relevant factor, while the communicative type and the pitch accent of the preceding utterance are significant predictors of the pitch accent that marks the particle, with the latter better explained the data. We propose that when analyzing the intonation of a dialect, semantic interpretation of the intonational constructions of the standard dialect should not be taken into account. Moreover, we suggest that a new approach of collecting prosodic data with elderly people while controlling for pragmatic context is needed
\end{abstract}

Keywords: Russian language, dialect, intonation, dialogue, politeness, yes and no

DOI: $10.28995 / 2075-7182-2021-20-403-412$

\section{Интонация да и нет в архаическом говоре с пословным тональным оформлением}

\author{
Князев С. В. \\ Институт русского языка \\ им. В. В. Виноградова РАН, \\ Москва, Россия \\ svknialgmail.com
}

\author{
Пронина М. К. \\ Университет Помпеу Фабра, \\ Барселона, Испания \\ mariia.pronina@upf.edu
}

\section{1 Введение: русские говоры с пословным тональным оформлением}

В процессе коммуникации значительная часть информации транслируется говорящим при помощи фразовой просодии, в некоторых случаях даже бо́льшая, чем та часть, что передается при помощи лексических значений слов. Так, например, высказывание Закройте дверь!, оформленное при помощи восходящего акцента на слове закройте является (и воспринимается) в современном русском литературном языке (СРЛЯ) гораздо более вежливым, чем высказывание $3 a-$ кройте, пожалуйста, дверь!, оформленное при помощи нисходящего акцента на том же слове. Однако система интонационных значений в разных языках и в разных диалектах одного языка может существенно различаться. Данное исследование посвящено анализу тональных акцентов в одном из архаических русских говоров.

В июле 1987 г. один из авторов в составе диалектологической экспедиции МГУ им. М. В. Ломоносова и Института русского языка им. В. В. Виноградова РАН посетил с целью сбора 
диалектного материала деревню Вадюга Верхнетоемского района Архангельской области в верховье реки Пинеги ${ }^{1}$.

Одной из самых ярких диалектных особенностей верхнепинежских говоров является их специфическая интонация [10], которая в значительной степени связана с особым типом использования тональных просодических средств, так называемым пословным тональным оформлением высказывания: «фраза состоит из ряда отрезков с восходящей интонацией, последний же отрезок характеризуется восходяще-нисходящей интонацией с более быстрым падением чем восхождением» [7: 14], «почти каждое слово во фразе получает свое мелодическое оформление» [9: 64], так что для этих говоров «характерно пословное оформление интонационного контура» [9: 78]. Тональную обособленность каждого слова в этих говорах фиксировала и Е. А. Брызгунова [3: 247, 262]. Примеры разных типов тонального оформления приведены на рис. 1 и 2: в фонетической синтагме СРЛЯ лишь одно слово выделено изменением частоты основного тона (ЧОТ), в то время как в говоре тональное изменение наблюдается на каждом фонетическом слове.

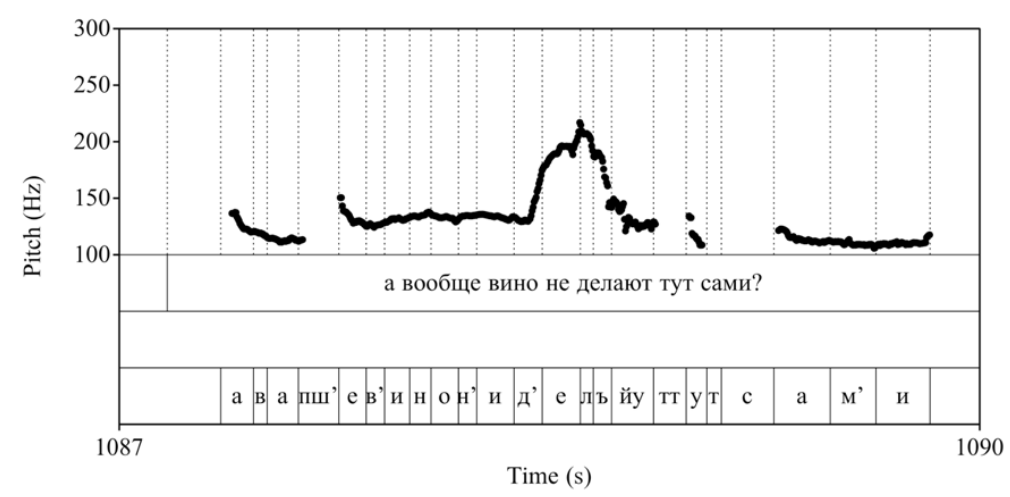

Рисунок 1: Кривая ЧОТ фразы А вообще вино не делают тут сами? (СРЛЯ)

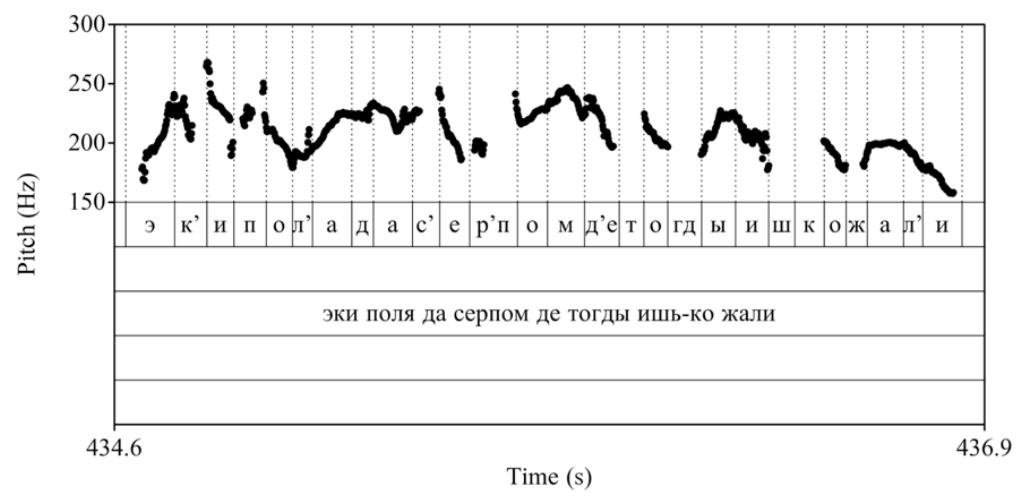

Рисунок 2: Кривая ЧОТ фразы Эки поля да серпом де тогды ишь-ко жали (д. Вадюга)

Кардинальные отличия диалектных систем рассматриваемого типа в области интонационного оформления высказывания от литературного языка приводят к тому, что взаимопонимание между носителями ЛЯ и диалекта может быть существенно затруднено - так, в ходе нашей экспедиции ее участники долгое время испытывали серьезные проблемы с восприятием диалектной речи, что, в целом, не свойственно ситуации нахождения носителя ЛЯ в диалектном окружении.

Другой проблемой в общении с носителями вадюжского диалекта на начальном этапе работы было, по отзывам участников, постоянное ощущение того, что носители говора в высшей степени неприветливы и недоброжелательны - основной причиной такого восприятия диалога являлась, в том числе, специфическая интонация ответных реплик носителей диалекта, близкая к

\footnotetext{
${ }^{1}$ В 1928-1929 гг., этот говор был исследован П. С. Кузнецовым [7]; описание его состояния в конце 1980-х гг. в сопоставлении с данными П. С. Кузнецова см. в [5].
} 
той, что в СРЛЯ описывается как четвертая интонационная конструкция (ИК-4) ${ }^{2}$ [4: 115]. В ИК4 предцентровая часть произносится на среднем тоне; если центр ИК находится в конце, тон начинается с более низкой точки по сравнению со средним, затем в пределах слога ровно повышается; если есть заударная часть, то ударная произносится с понижением, а заударная - с ровным повышением тона [2: 41]. Использование ИК-4 в диалектной речи отмечалось не раз [3], в частности, - в утвердительных предложениях [10: 60-61, 63] и в ответных репликах в диалоге [13: 109]. Е. А. Брызгунова, описывая один из пинежских диалектов, отмечает: «Одной из ярких особенностей, “экзотикой” интонации говора д. Ваймуша Архангельской обл. является модальная реализация ИК-4, отмеченная в ситуации, когда говорящий что-либо доказывает, спорит, возражает» [3: 241]. В литературном языке «ИК-4 употребляется наряду с ИК-1, подчеркивая при этом противопоставление, категоричность утверждения, удивление, вызов» [4: 115].

Итак, постоянно слыша в диалогах с информантами интонацию, близкую к ИК-4 литературного языка, мы воспринимали ее как показатель ненейтрального отношения говорящего - раздражения, вызова, категоричности утверждения и даже нежелания поддерживать разговор. Однако данный тип просодического оформления высказывания встречается в говоре настолько часто, что это заставляет задуматься о том, действительно ли соответствующий интонационный контур не является эмоционально нейтральным.

\section{2 Цели, задачи, материал и процедура исследования}

Целью данного исследования, таким образом, был анализ интонационного оформления ответных диалогических реплик, основной задачей - поиск закономерностей в распределении нисходящего и восходящего тонального акцента в просодическом оформлении утвердительной и отрицательной частиц $\partial a$ и нет. Утвердительная и отрицательная частицы были выбраны в качестве материала исследования в силу того, что они являются наиболее частыми словами в существующих текстах и обладают достаточно очевидной семантикой.

Запись материала в ходе экспедиции 1987 г. производилась автором данной статьи на кассетный стереомагнитофон «Соната 213С» с использованием выносных динамических микрофонов, впоследствии записи были оцифрованы А. В. Архиповым. В настоящее время продолжается работа по созданию корпуса звучащих текстов говоров Верхнетоемского района Архангельской области, куда эти записи будут включены. В большинстве случаев тексты представляют собой беседы интервьюеров с носителями диалектов, в редких случаях - диалоги носителей говора.

Материалом для настоящего исследования служили записи, полученные от трех носителей анализируемого говора. В ходе основного эксперимента были проанализированы записи информанта ПЕМ, женщины 70 лет, который был выбран на основании того, что, во-первых, он является одним из наиболее типичных представителей анализируемого говора (в том числе и в отношении фразовой просодии), во-вторых, относится к старшему его поколению, сохраняющему диалектную основу в максимальной степени, в-третьих, от него имеются записи максимальной продолжительности (90 минут звучания, 141 тестовое слово). Дополнительная верификация полученных данных была проведена на материале реплик еще двух информантов женского пола МИР (87 лет, 59 слов) и АПН (62 года, 40 слов).

На первом этапе исследования была проведена сплошная аннотация 2741 реплики ${ }^{3}$ основного информанта (ПЕМ), затем были выделены контексты с частицами $\partial а$ и нет (общее количество 141) и с помощью программы PRAAT осуществлен анализ их тонального оформления.

Полученные данные свидетельствуют о том, что тональное оформление частиц $\partial a$ и нет в исследуемом говоре достаточно вариативно: они могут быть оформлены следующими мелодическими контурами: восходящее движение тона ${ }^{4}$ (см. рис. 3 ), ровное + восходящее (см. рис. 4), нисходяще-восходящее (см. рис. 5), восходяще-нисходящее (см. рис. 6), нисходящее (см. рис. 7), ровное + нисходящее (см. рис. 8).

\footnotetext{
${ }^{2}$ В действительности, этот тип интонационного оформления отличается от ИК-4 литературного языка, но в настоящей работе мы не будем останавливаться на этих различиях, данному вопросу посвящено отдельное исследование.

${ }^{3}$ Репликами в данном случае считаются звучащие отрезки между физическими (в том числе - дыхательными) паузами, их продолжительность колеблется в диапазоне от 0,1 до 8,5 секунд.

${ }^{4}$ Восходящее движение в чистом виде фиксируется только в тех случаях, когда частица включена в более широкий просодический контекст, то есть, не является отдельной фонетической синтагмой.
} 


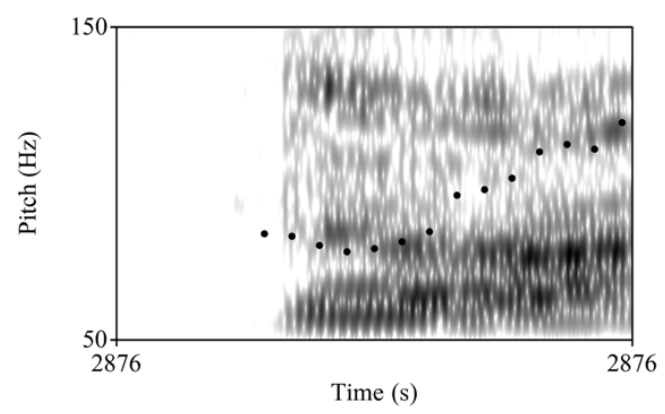

Рисунок 3: Динамическая спектрограмма и кривая ЧОТ (Да, восходящее движение ЧОТ) ${ }^{5}$

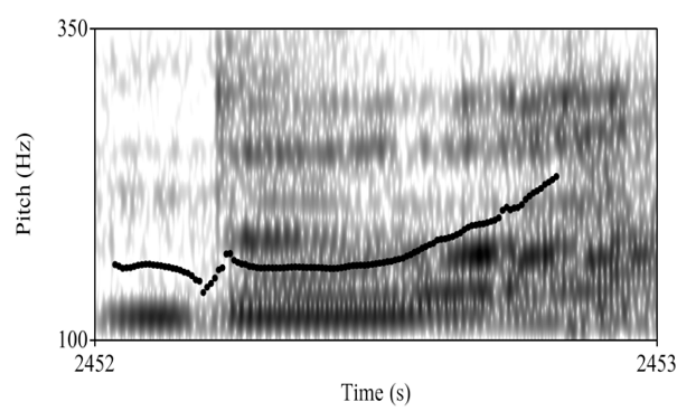

Рисунок 4: Динамическая спектрограмма и кривая ЧОТ (Да, ровное + восходящее движение)

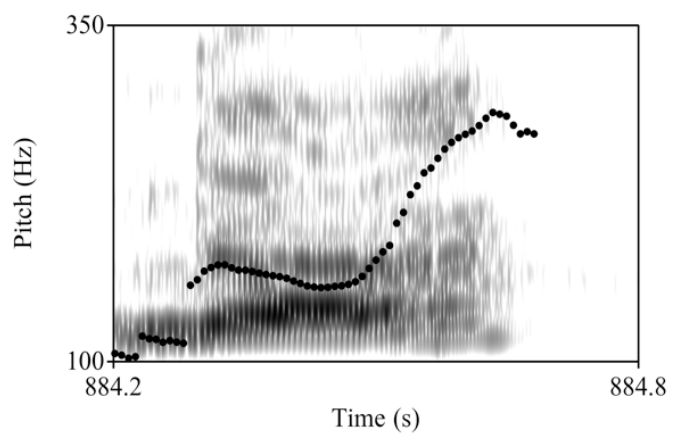

Рисунок 5: Динамическая спектрограмма и кривая ЧОТ

(Да, нисходяще-восходящее движение)

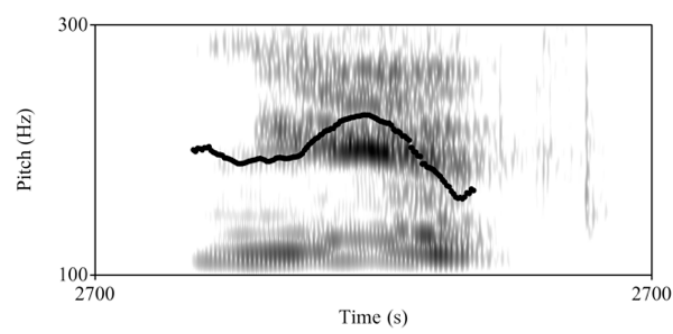

Рисунок 6: Динамическая спектрограмма и кривая ЧОТ

(Hет, восходящее + нисходящее движение)

\footnotetext{
${ }^{5}$ Незначительное понижение тона в начале частицы является в данном случае микропросодическим: это автоматическое изменение ЧОТ на звонком взрывном [д].
} 


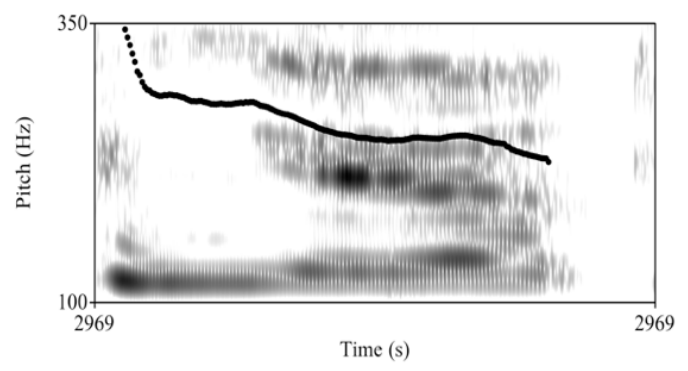

Рисунок 7: Динамическая спектрограмма и кривая ЧОТ (Нет, нисходящее движение)

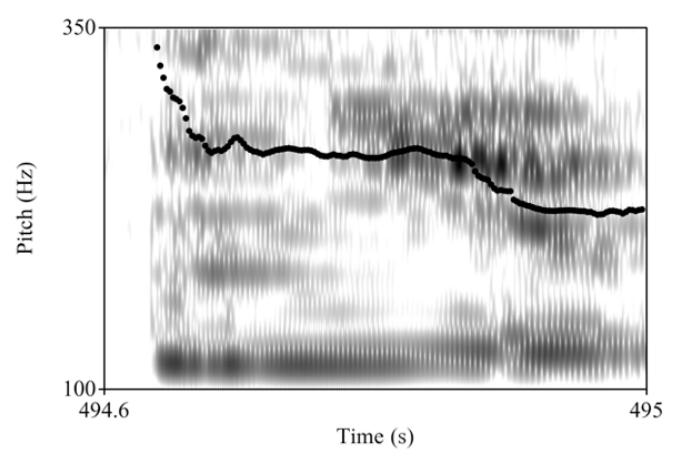

Рисунок 8: Динамическая спектрограмма и кривая ЧОТ

(Нет, ровное + нисходящее движение)

В целом, всё это разнообразие может быть сведено, однако, к противопоставлению восходящего акцента, сходного с ИК-4 литературного языка (рис. 3 - 5), и нисходящего (с возможным ровным или восходящим участком в начале), сходного с ИК-1 и ИК-2 (рис. $6-8$ ).

\section{3 Результаты и обсуждение}

Одной из рабочих гипотез исследования было предположение о том, что в исследуемом говоре частицы $\partial a$ и нет интонируются по-разному: утвердительная - преимущественно с восходящим акцентом, отрицательная - с нисходящим (см. выше рис. $3-8$, на которых все вхождения $\partial a$ оформлены восходящим движением ЧОТ, а все вхождения нет содержат нисходящее движение).

Результаты исследования представлены в таблице 1 . Всего в проанализированных текстах встретилось 141 вхождение $\partial a$ и нет (104 и 37 соответственно $)^{6}$, в трех случаях (2 $\partial a$ и 1 нет) определить характер изменения ЧОТ оказалось невозможным вследствие дефектов записи, таким образом, всего было проанализировано 138 случаев $(102+36)$.

\begin{tabular}{|l|ll|l|}
\hline & da & неm & всего \\
\hline всего проанализировано & 104 & 37 & 141 \\
получены данные & 102 & 36 & 138 \\
нисходящий тон (кол-во) & 22 & 5 & 27 \\
нисходящий тон (\% от общего числа) & $22 \%$ & $14 \%$ & $20 \%$ \\
\hline
\end{tabular}

Таблица 1: Нисходящий тон на частицах $\partial a$ и нет: количество случаев, \% от общего числа

На основании представленных в таблице данных можно заключить, что нисходящее (реже в сочетании с предшествующим ровным) движение тона в репликах информанта зафиксировано в $20 \%$ всех случаев (27 вхождений): 5 на нет; 22 на $\partial a$. Уже этот факт позволяет усомниться в том,

\footnotetext{
${ }^{6}$ В четырех случаях частицы представлены в одной реплике дважды, в одном - трижды.
} 
что восходящее движение тона на утвердительной и отрицательной частицах да и нет маркирует эмоции информанта («акцент вызова» по Е. А. Брызгуновой): сложно представить, что носитель диалекта лишь в одном случае из пяти использует нейтральное просодическое оформление $\partial a$ и нет. Тем не менее, для проверки рабочей гипотезы о том, что интонация зависит от семантики самих слов (утвердительная частица оформляется восходящим акцентом, а отрицательная - нисходящим) была построена бинарная логистическая регрессия в среде $\mathrm{R}$, версия 4.0.2 (R Core Team, 2020), с использованием функции glm. В качестве предиктора был задан типа семантики (да vs. нет), а зависимой переменной был тип интонационного контура (восходящий vs. нисходящий). Информационный критерий Акаике (AIC) модели достиг 137.45. Результаты показали, что тип семантики не является значимым предиктором $(\beta=0.457, p=0.399)$.

В связи с полученными результатами была предпринята попытка поиска иных факторов, объясняющих распределение восходящего и нисходящего акцентов на одних и тех же словах в исследуемом говоре. Анализ реплик, оформленных понижением тона, позволят предположить, что таким фактором является тип левого контекста - характер предшествующей реплики ${ }^{7}$ : нисходящий акцент на частицах $\partial а$ и нет встречается преимущественно в тех случаях, когда предшествующая реплика является утверждением (в том числе - утверждением самого информанта), а не вопросом, см. ниже таблицу 2. Таких случаев, не вызывающих сомнений, в нашем материале зафиксировано 21 из общего числа в 26 реплик с нисходящим тоном (81\%); исключениями являются 5 реплик, в которых нисходящий тон отмечен на частицах, которые могут быть интерпретированы как ответы на вопрос. Наоборот, восходящий акцент на частицах да и нет в подавляющем большинстве случаев отмечен после вопроса (в том числе - самого информанта). Несомненных случаев такого рода зафиксировано 101 из общего числа в 111 (91\%); случаев, которые могут быть интерпретированы как исключения из данной закономерности, зафиксировано 10.

\begin{tabular}{|l|ll|l|}
\hline Предшествующая реплика & Восходящий тон & Нисходящий тон & Всего \\
\hline Вопрос & $101(91 \%)$ & $5(19 \%)$ & 106 \\
Утверждение & $10(9 \%)$ & $21(81 \%)$ & 31 \\
\hline
\end{tabular}

Таблица 2: Нисходящий или восходящий тон на частицах да и нет в зависимости от семантики предшествующей реплики: количество случаев, \% от общего числа

Как представляется, для описания наблюдаемой в говоре картины распределения нисходящего и восходящего акцентов на частицах $\partial a$ и нет можно предложить два разных объяснения - коммуникативное, и фонетическое. Первое могло бы быть связано со структурой диалога, распределением в нем ролей и способами передачи реплики собеседнику (turn allocation). Одним из способов такой передачи в русском языке как раз и является восходящий тон [8], и ИК-4 часто служит в СРЛЯ для маркирования того факта, что говорящий заинтересован в продолжении разговора ср. интонационное оформление отрывка из одного из рассказов С.Довлатова:

(1) Девушка-экскурсовод ела мороженое в тени. Я шагнул к ней:

- Давайте познакомимся.

- Авро ${ }^{1}$ ра, - сказала она, протягивая липкую руку.

(2) Девушка-экскурсовод ела мороженое в тени. Я шагнул к ней:

- Давайте познакомимся.

- Авро ${ }^{4}$ ра, - сказала она, протягивая липкую руку.

В (1) ответ является нейтральным, и интонация ИК-1 никак не свидетельствует о желании или нежелании одного из участников продолжать диалог, в то время как ИК-4 в (2) является сигналом заинтересованности в продолжении разговора. Можно предположить, что в анализируемом говоре при подтверждении $(\partial a)$ или отрицании (неm) утверждения или состояния дел используется нисходящий акцент, поскольку дальнейший диалог в этом случае не предполагается. Наоборот, в

\footnotetext{
${ }^{7}$ В противоположность этому, в литературном русском языке да «как правило, несет на себе интонацию другой реплики, которая за ней следует» [6: 330]. Укажем в этой связи, что в нашем материале почти в половине всех случаев (69 из 141, 49\%) частицы $\partial a$ и нет представляли собой законченные высказывания (без дальнейших реплик того же участника диалога), а в значительной части оставшихся частицы были включены в общий тональный контур реплики, что не позволило проанализировать влияние этого параметра на характер тонального оформления частиц.
} 
случае подтверждения $(\partial a)$ или отрицания (нет) информации, заключенной в общем вопросе, имеет место восходящий тон (сходный с ИК-4), свидетельствующий о готовности к продолжению разговора и маркирующий готовность к передаче реплики собеседнику, что как раз является более вежливым просодическим оформлением в подобной ситуации, нежели нисходящий акцент, близкий ИК-1. Впрочем, есть и сильные аргументы против этой гипотезы. Во-первых, восходящий акцент в говоре используется и в ответах на вопрос, содержащийся в собственной реплике. Во-вторых, в ответах на реплики, являющиеся по своей семантике вопросами, но оформленные нисходящим движением тона, фиксируется нисходящий тон; наоборот, в реакциях на реплики, не являющиеся по своей семантике вопросами, но оформленные восходящим движением тона, имеет место восходящий акцент (всего 7 примеров). На этом основании можно сформулировать фонетическое объяснение: характер просодического оформления частиц $\partial a$ и нет зависит в говоре от типа акцента на предыдущей реплике.

Для проверки коммуникативной и фонетической гипотезы были построены две бинарные логистические регрессии. В обеих моделях тип интонационного контура на частице (восходящий vs. нисходящий) был задан в качестве зависимой переменной, но в первой модели предиктором выступал характер предшествующей реплики (утверждение vs. вопрос), в то время как во второй - характер изменения ЧОТ на предшествующей реплике (нисходящий vs. восходящий). Результаты показали, что как характер предшествующей реплики, так и направление движения тона на ней являются значимыми предикторами типа интонационного контура на частице $(\beta=-3.733, p$ $<.000$ и $\beta=-6.062, p<.000$, соответственно). Критерий АІС первой модели равен 83.45 , второй - 46.09. Критерий AIC применяется для выбора из нескольких статистических моделей: чем ниже критерий, тем лучше модель описывает данные. Из этого можно сделать вывод, что “фонетическая” модель работает лучше. Соответствующие данные приведены ниже в таблице 3, а примеры, иллюстрирующие это положение, на рис. 9 - 12, где хорошо видно полное совпадение тонального оформления ответной реплики с предшествующей ей вне зависимости от коммуникативного типа реплики-стимула.

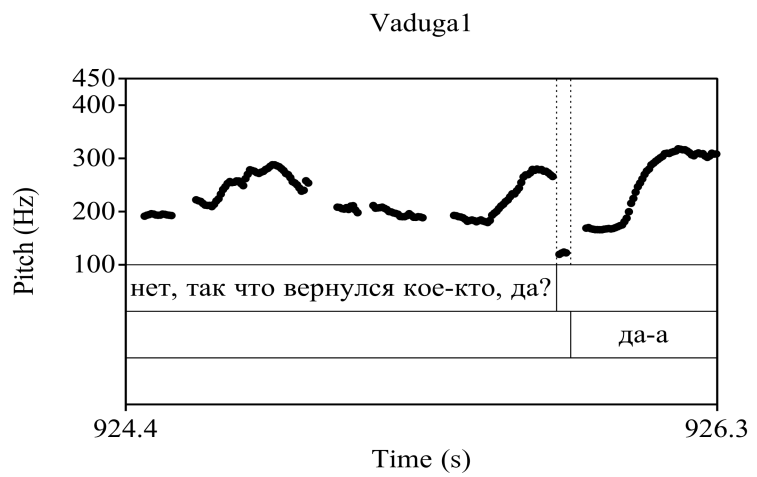

Рисунок 9: Интонограмма реплик - Нет, так что вернулся кое-кто, да? - Да-а. (ровное + восходящее движение тона на обеих репликах)

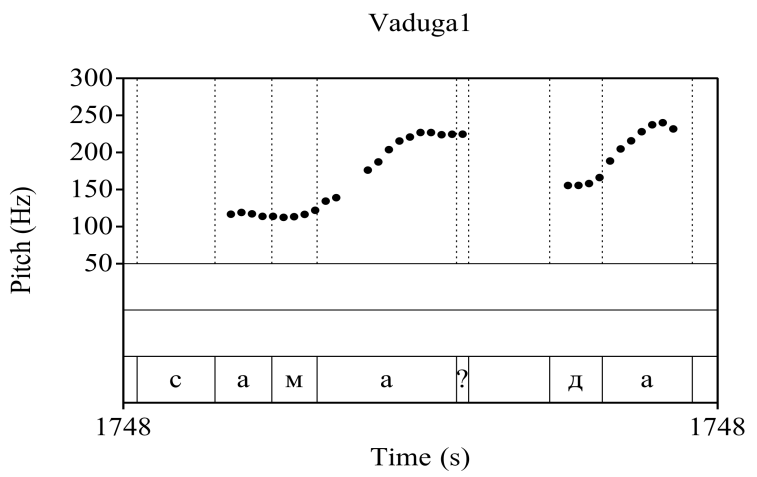

Рисунок 10: Интонограмма реплик - Сама? - Да-

(ровное + восходящее движение тона на обеих репликах) 


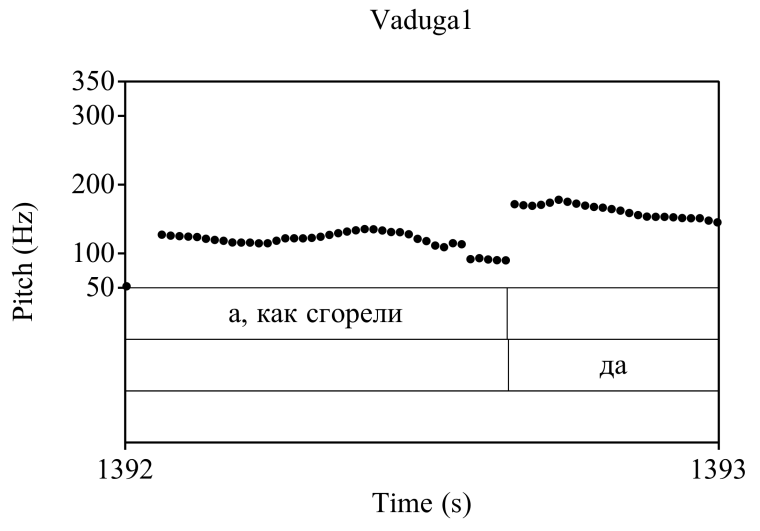

Рисунок 11: Интонограмма реплик - A, как сгорели. - Да. (нисходящее движение тона на обеих репликах)

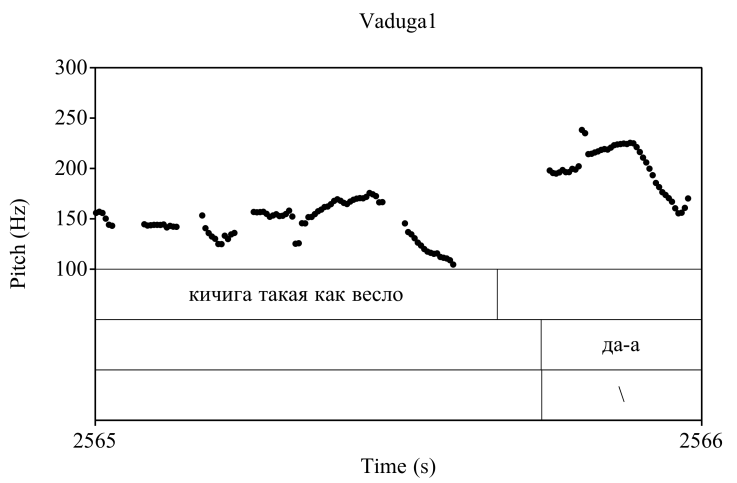

Рисунок 12: Интонограмма реплик - Кичига такая, как весло. - Да-а.

(восходяще-нисходящее движение тона на обеих репликах)

На основании приведенных данных можно заключить, что выбор нисходящего или восходящего тона на частицах $\partial a$ и нет в ответных репликах обусловлен фонетически и копирует тон предшествующей реплики, то есть, верным является фонетическое объяснение, которое позволяет существенно уменьшить число тех реплик, которые иначе пришлось бы считать исключениями. Их список может быть сокращен не только на 7 примеров, описанных выше и не противоречащих фонетической гипотезе, но и доведен до минимума, т.к. 1) нисходящий тон в двух репликах обусловлен не ответом на вопрос собеседника, а низким тоном предшествующей реплики другого информанта (при этом в одной из реплик вопрос интервьюера задан так тихо, что не мог быть расслышан информантом) - таким образом, для нисходящего тона на $\partial a$ и нет исключений не остается вовсе; 2) в одном из случаев ответ относится к первой части реплики, оформленной восходящим тоном, а не ко второй - с нисходящим; 3) в двух случаях частица включена в общий просодический контур высказывания, поэтому движение тона на ней может не быть показательным. Тем самым, настоящих «исключений» (восходящий тон после реплики с нисходящим) оказывается только 3 из 138 (2\%); возможно, как раз они представляют собой эмоциальные реакции.

\begin{tabular}{|l|ll|l|}
\hline Предшествующая реплика & Восходящий тон & Нисходящий тон & Всего \\
\hline Восходящий тон & $108(98 \%)$ & $0(0 \%)$ & 108 \\
Нисходящий тон & $3(2 \%)$ & $26(100 \%)$ & 29 \\
\hline
\end{tabular}

Таблица 3: Нисходящий или восходящий тон на частицах $\partial а$ и нет в зависимости от характера изменения ЧОТ на предшествующей реплике: количество случаев, \% от общего числа

Для дополнительной верификации результатов проведенного эксперимента были проанализированы данные еще двух носителей верхнепинежского диалекта, собранные в ходе той же 
экспедиции (МИР и АПН, см. выше раздел “Материал”). В общей сложности было выявлено еще 99 реплик с частицами $\partial a$ и нет. На основе этих данных были построены три бинарные логистические регрессии для проверки семантической, коммуникативной и фонетической гипотез. В спецификации семантической модели предиктором выступал тип семантики частицы (“да” / “нет”), коммуникативной - характер предшествующей реплики (утверждение / вопрос), фонетической тип тона предшествующей реплики (нисходящий / восходящий). Во всех трех моделях зависимой переменной являлся тип интонационного контура на частице (восходящий vs. нисходящий). Полученные результаты подтвердили, что тип семантики не является значимым ( $\beta=-0.176, p=.805)$, в то время как характер и тип тона предшествующей реплики - значимые предикторы $(\beta=-4.407$, $p<.000$ и $\beta=-5.730, p<.000$, соответственно). Критерий AIC фонетической модели был выше аналогичного критерия коммуникативной модели (29.42 и 42.00, соответственно). Таким образом, как и в основном анализе, модели, построенные на дополнительных данных, показали, что тип тона на частице зависит от обоих факторов (характер предшествующей реплики и тип тона предшествующей реплики), однако фонетическая модель лучше объясняет данные.

\section{4 Выводы}

Один из основных выводов, который можно сформулировать на основании результатов настоящего исследования, заключается в том, что при анализе диалектной интонации не следует ориентироваться на семантическую интерпретацию интонационных конструкций СРЛЯ, поскольку диалект - это другая языковая система, в которой мелодические контуры, даже весьма сходные с литературными, могут передавать совсем другие значения. Очевидно, что вопреки первым впечатлениям о диалекте его носители не отвечают на вопросы собеседников невежливо - категорично, с вызовом или подчеркивая противопоставление [4: 115] - вполне возможно, что как раз наоборот, не будучи уверенными в том, какова именно семантика того или иного мелодического контура в реплике собеседника, говорящего на литературном языке, они из вежливости копируют в ответе основные тональные характеристики этого контура.

Полученные в ходе настоящего исследования данные свидетельствуют, на наш взгляд, еще и о том, что требуется дальнейшее изучение фразовой просодии русских диалектов, особенно в направлении не от формы к значению, поскольку точно оценить семантику, передающуюся в говоре при помощи просодии в таком случае оказывается очень сложно, а от содержания к форме: каким именно образом передаются те или иные коммуникативные значения в диалекте. Подавляющее большинство доступных в настоящий момент диалектных текстов представляют собой либо монологи носителей говора, либо диалоги, в которых вопросы задает диалектолог, поэтому большая часть коммуникативных типов в речи носителя либо не встречается вовсе, либо встречается крайне редко, а для тех, что встречаются, как показало данное исследование, представляется в высшей степени затруднительным оценить их семантику на основании наших знаний о литературной фразовой просодии, особенно при использовании системы ИК, в которой основным компонентом каждого мелодического контура является изначально заданная семантика. Поэтому, на наш взгляд, необходим иной подход к сбору диалектного материала для просодических исследований. Он должен быть организован таким образом, чтобы в текстах встречались все необходимые коммуникативные типы с известной заранее семантикой, желательно, на сопоставимом для всех исследуемых языковых систем и удобном для фонетического анализа звуковом материале; при этом он должен быть удобным для работы с информантами старшей возрастной категории, зачастую неграмотными или не способными по разным причинам работать с письменными инструкциями. Наиболее адекватным методом для решения этой задачи, как представляется, может служить Discourse Completion Task (DCT) - метод, адаптированный для просодических исследований из работ в области прагматики; он успешно используется для элиситации разных типов интонационных контуров и получил широкое распространение для описания интонации разных языков, прежде всего, романской группы [14]. При использовании DCT информантам предлагается дополнить (complete) каким-либо высказыванием с заданным коммуникативным значением краткий диалог или ситуацию из их повседневной жизни [1]. Применение этого метода позволит не только элиситировать предложения с заданной прагматикой, но и сравнить их просодическую реализацию в речи разных носителей, все это поможет получить надежные результаты о репертуаре просодических средств данного диалекта и их значениях. 


\section{References}

[1] Barron, Anne. Acquisition in interlanguage pragmatics: Learning how to do things with words in a study abroad context. Amsterdam: John Benjamins, 2009.

[2] Bryzgunova E. A. Zvuki i intonatsiya russkoy rechi [Sounds and intonation of Russian speech]. Moscow, 1969 (In Russ.)

[3] Bryzgunova, E. A. Analiz russkoy dialektnoy intonacii [An analisys of Russian dialectal intonation] In: Eksperimental'no-foneticheskie issledovaniya v oblasti russkoy dialektologii [Experimental phonetic studies in the field of Russian dialectology]. Moscow, Nauka, 1977. P. 231-262 (In Russ.)

[4] Bryzgunova E. A. (Intonatsiya [Intonation]. In: Russkaya grammatika [Russian Grammar]. M.Yu.Svedova (ed.). Vol. I. Moscow, Nauka, 1980 (In Russ.)

[5] Knyazev S.V., Levina A.N., Pozharitskaya S.K. O govorax Verxney Pinegi i Vyi [On Upper Pinega and Vyya dialects]. In: Russkie dialekty: istoriya i sovremennost'. Problemy russkogo yazykoznaniya [Russian dialects: history and present state. Problems of Russian linguistics. VII]. Moscow, Moscow State University Publ., 1997. P. 198-220 (In Russ.)

[6] Kodzasov S. V. Studies in Russian prosody. Moscow, Yazyki Slavyanskikh Kul'tur, 2009 (In Russ.)

[7] Kuznetsov P. S. O govorax Verxney Pinegi i Verxney Toymy [On Upper Pinega and Upper Toyma dialects]. In: Materialy i issledovaniya po russkoy dialektologii. Tom 1 [Materials and studits in Russian dialectology. Vol. 1] Moscow - Leningrad, 1949. P. 5-44 (In Russ.)

[8] Paschen L. Boundary tones indicate turn allocation in Russian. In Proceedings of ConSOLE XXII, Leiden, 2015.

[9] Paufoshima, R. F. Fonetika slova i frazy v severnorusskix govorax [Phonetics of word and phrase in Northern Russian dialects]. Moscow, Nauka, 1983 (In Russ.)

[10] Paufoshima, R. F. Ob ispol'zovanii registrovyx razlichiy v russkoy frazovoy intonatsii (na materiale russkogo literaturnogo yazyka i severnorusskix govorov) [On the use of tone-level differencies in russian phrase intonation (based on data from Standard Russian an Northern Russian dialects)]. In: Slavyanskoe i balkanskoe yazykoznanie. Prosodiya [Slavic and Balkan linguistics. Prosody]. Moscow, Nauka, 1989 (In Russ.)

[11] R Core Team. R: A language and environment for statistical computing. Foundation for Statistical Computing, 2020. https://www.r-project.org/.

[12] Rodero, Emma/ Intonation and Emotion: Influence of Pitch Levels and Contour Type on Creating Emotions. Journal of Voice. Volume 25, Issue 1, January 2011, P. 25-34.

[13] Shchigel' E. V. Osobennosti intonacionnoy organizacii frazy v nekotoryx severnorusskix govorax [Peculiar properties of intonational structure in some Northern Russian dialects]. In: Dialektografiya russkogo yazyka [Dialectografy of Russian]. Moscow, Nauka, 1985. P. 102-111 (In Russ.)

[14] Vanrell, Maria del Mar, Feldhausen, Ingo \& Lluïsa Astruc. The Discourse Completion Task in Romance prosody research: Status quo and outlook. In: Ingo Feldhausen, Jan Fliessbach \& Maria del Mar Vanrell (eds.), Methods in prosody: A Romance language perspective, 191-227. Berlin: Language Science Press, 2018. 